\title{
Photochemical Mechanism for the Air Inflammation Propagation
}

\author{
Fedotov V G* and Fedotova E Y \\ N.N. Semenov Federal Research Center for Chemical Physics, Russian Academy of Sciences, Russian Federation, Moscow \\ *Corresponding author: Fedotov VG, N.N. Semenov Federal Research Center for Chemical Physics, Russian Academy of \\ Sciences, Russian Federation, Moscow
}

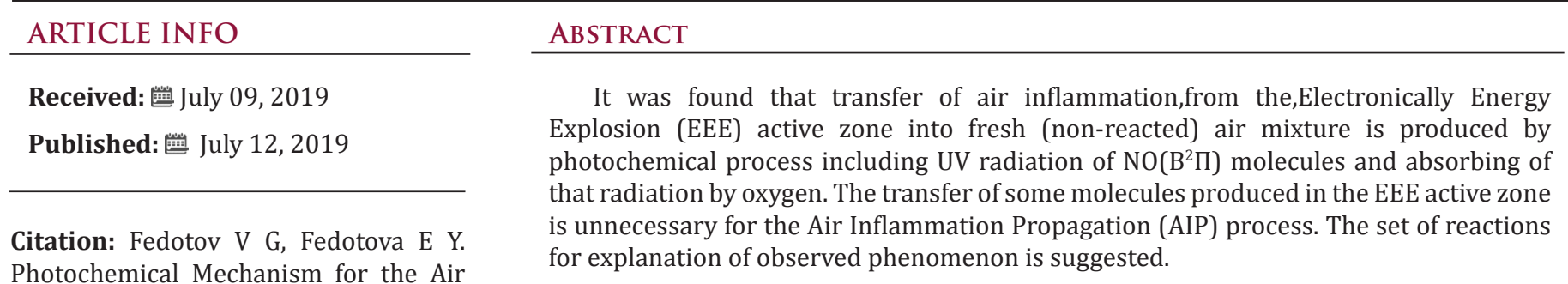
Inflammation Propagation. Biomed J Sci \& Tech Res 19(4)-2019. BJSTR. MS.ID.003328.

Keywords: Electronic Energy Explosion in Air; Air Inflammation propagation (AIP); Nitrogen Oxidation Chain Reaction; Electronically Excited Particles; Photons; $\mathrm{O}_{2}\left(\mathrm{~A}^{3}{ }^{\mathrm{\Sigma}}{ }_{\mathrm{u}}\right)$; $\mathrm{NO}\left(\mathrm{B}^{2} \Pi\right) ; \mathrm{O}\left({ }^{1} \mathrm{~S}\right)$

\section{Introduction}

The Electronic Energy Explosion (EEE) in the air can be initiated by electrical discharge near the ferrite surface [1]. The EEE active zone can be characterized by very high concentrations of electronically excited particles. It was found earlier [2] that EEE active zone is able to propagate in space by some definite conditions. One of these conditions is the presence of light reflecting walls in the reactor [3]. In [4] we have formulated the assumption that radiation produced by $\mathrm{NO}\left(B^{2} \Pi\right)$ is responsible for AIP. This radiation is absorbed by $\mathrm{O}_{2}$ molecules with formation of $\mathrm{O}_{2}\left(\mathrm{~A}^{3} \Sigma^{+}{ }_{\mathrm{u}}\right)$ and initiation of nitrogen oxidation chain reaction. The last reaction causes a set of phenomena that we named "air inflammation". An experimental proof of such photochemical mechanism of AIP was the aim of this work.

\section{Methods}

For the proof of the photochemical way of AIP we used a $\mathrm{CaF}_{2}$ glass as a baffle inside a long cylindrical reactor $90 \mathrm{~mm}$ in diameter. Such baffle is transparent for UV and visible light, but it detains any molecules, keeping them of transferring from EEE active zone into fresh (non-reacted) air mixture. The transparent walls of reactor enabled to see and to record videos of air inflammation in all parts of reactor. The atmospheric pressure was used in these experiments. For inflammation propagation at such conditions the reactor was wrapped with $\mathrm{Al}$ foil in according with results of [3]. The same inflammation initiating arrangement was used as in works $[3,4]$ : it consisted of ferrite ring $16 \mathrm{~mm}$ in diameter and two steel electrodes pressed to the ferrite surface. The distance between the contact points of electrodes with ferrite was 3-4 mm. Two capacitors of $1000 \mu \mathrm{F}$ capacity charged to the voltage $220 \mathrm{~V}$ on each of them connected in sequence were joined to electrodes: one of the electrodes was constantly in contact with capacitors battery, another was connected through a switch.

After turning the switch on the $440 \mathrm{~V}$ voltage was applied to the discharge gap. The chart of electrical connections was described in [5] (Figure 1). Xiaomi Action Camera (Mi Action Camera 4K, Model: YDXJ01FM) was used for video recording of EEE. It provided the rate of recording equal 200 frames/s.

\section{Results}

Two adjacent frames of EEE video are placed on Figure 2. On the first one there is the image of EEE radiating bright blue light and filling the entire reactor volume in spite of $\mathrm{CaF}_{2}$ baffle positioned in the reactor at the place marked by one white arrow. On the second frame there is the image of EEE afterglow of orange-red color. It fills the entire reactor volume too. So, it can be seen that air inflammation is transferred in the part of reactor which was separated from the initiating unit by $\mathrm{CaF}_{2}$ baffle. 


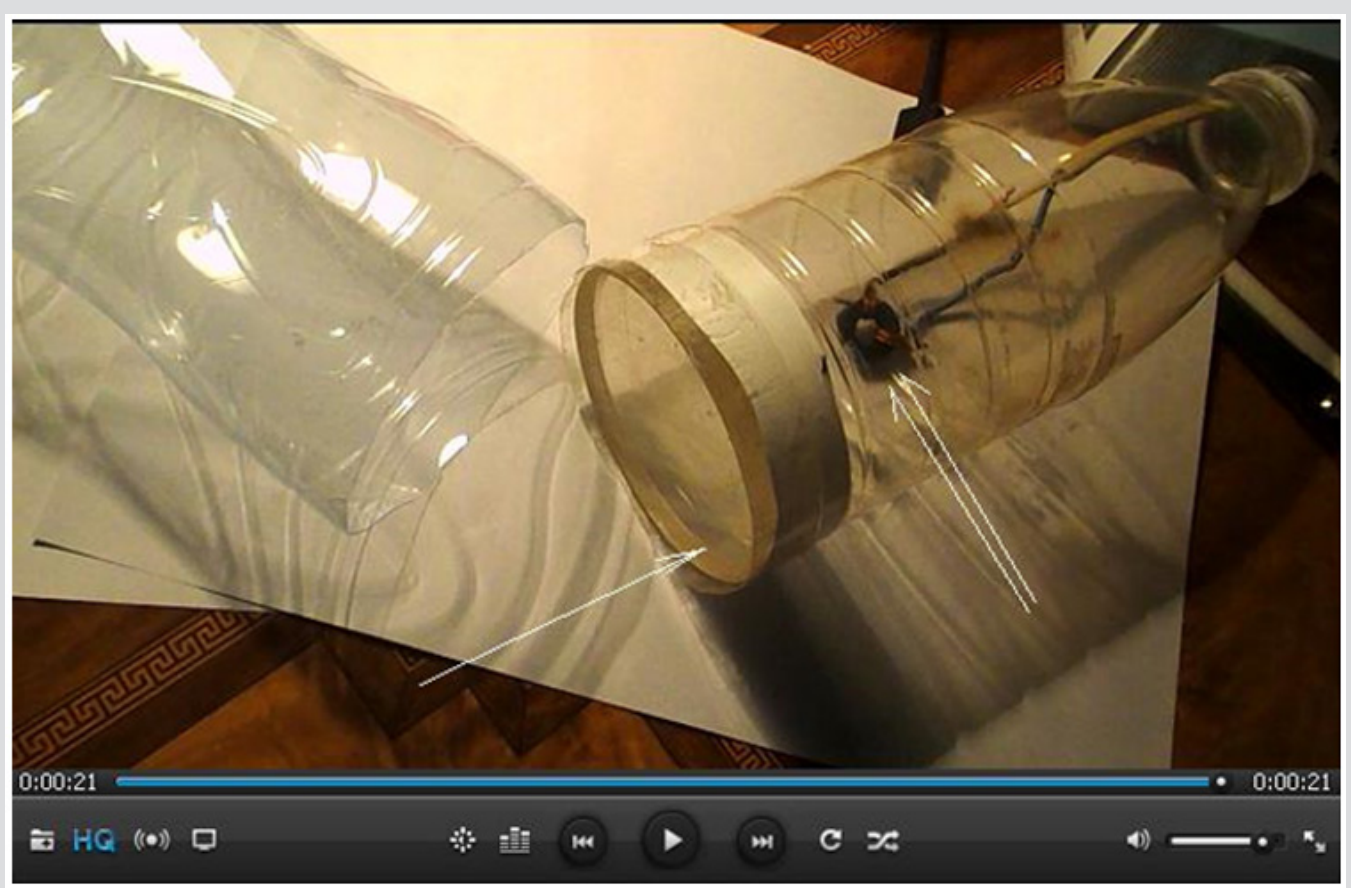

Figure 1: The photo of the initiating unit of the reactor. That unit contains $\mathrm{CaF}_{2}$ window (marked by one white arrow) and the ferrite ring with two steel electrodes pressed to it (marked by two white arrows). The rest part of the reactor can be seen to the left from the initiating unit. Before the experiment it must be joined to the initiating unit at the $\mathrm{CaF}_{2}$ end.

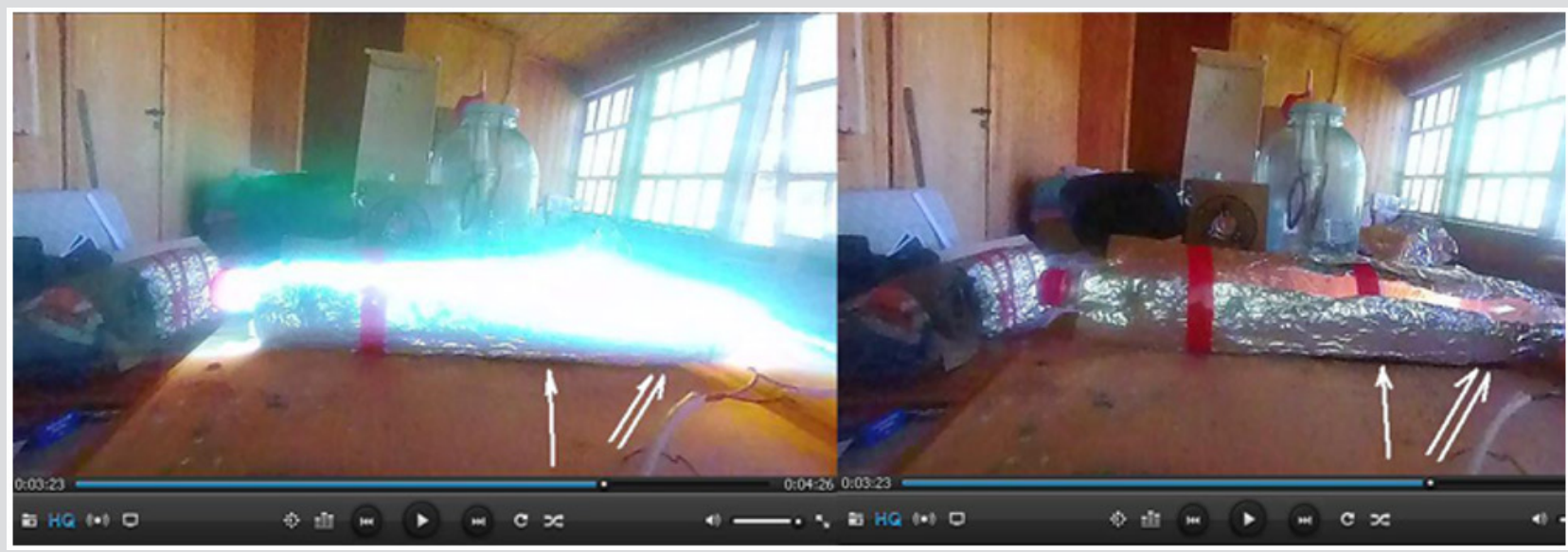

Figure 2: Two frames of video containing EEE in the reactor with $\mathrm{CaF}_{2}$ barrier. The Air Inflammation filled the entire volume of the reactor in spite of barrier presence at the place marked by one white arrow. Two white arrows are showing at the place where the ferrite ring was positioned. The left frame contains the EEE image. The right frame contains the EEE afterglow image.

\section{Discussion and Conclusion}

It is evident from presented experimental results that the AIP does not need some transfer of the molecules; the transfer of radiation (produced in EEE active zone) is sufficient. The spectrum of radiation produced in EEE active zone contains first of all the bands system of $\mathrm{NO}\left(B^{2} \Pi\right)$ molecules [1]. The most shirt-wave of these bands belong to the diapason 250-300 nm [6]. The Herzberg 1 bands system of $\mathrm{O}_{2}$ molecules belongs to that diapason [7]. The light absorbing in this band system results in appearance of $\mathrm{O}_{2}(\mathrm{~A}$ ${ }^{3} \Sigma_{\mathrm{u}}^{+}$) molecules with energy $4.3 \mathrm{eV}$. The interaction of two such excited molecules can produce $\mathrm{O}\left({ }^{1} \mathrm{~S}\right)$ atom:

$$
O_{2}\left({ }^{3} \Sigma^{+}{ }_{u}\right)+O_{2}\left({ }^{3} \Sigma_{u}^{+}\right)=>O_{3}+O\left({ }^{1} S\right)
$$

These atoms are able to initiate the nitrogen oxidation chain reaction [8]:

$$
\begin{aligned}
& O\left({ }^{1} S\right)+N_{2}+M=>O\left({ }^{1} S\right)-N_{2}+M \\
& \mathrm{O}\left({ }^{1} \mathrm{~S}\right)-\mathrm{N}_{2}+\mathrm{O}=>\mathrm{NO}\left(\mathrm{B}^{2} \Pi\right)+\mathrm{NO} \\
& \mathrm{NO}+\mathrm{O}_{2}+\mathrm{M}=>\mathrm{NO}_{3} \\
& \mathrm{NO}\left(B^{2} \Pi\right)+\mathrm{NO}_{3}=>\mathrm{NO}_{2}+O\left({ }^{1} S\right)
\end{aligned}
$$

The assumption about reactions (1), (3), (5), which need the interaction between two active particles, can explain why the EEE 
initiation needs some big enough amount of energy (for example the constantly present cosmos radiation is not enough for EEE in the air initiation).

\section{References}

1. Fedotov VG, Fedotova EY (2015) Explosion in atmospheric air initiated by electric discharge and associated with the growth of the concentrations of electronically excited molecules and free charges. Russian J Phys Chem B 9(2): 223-227.

2. Fedotov VG, Fedotova EY (2018) Conditions for propagation of air inflammation. Biomed J Scien \&Technol Res 11(2): 8396-8397.

3. Fedotov VG, Fedotova EY (2019) Conditions for propagation of air inflammation in the reactor with reflecting walls. Biomed J Scien \& Technol Res 16(3): 1-3.

\section{ISSN: 2574-1241}

DOI: 10.26717/BJSTR.2019.19.003328

Fedotov V G. Biomed J Sci \& Tech Res

cC) This work is licensed under Creative Commons Attribution 4.0 License

Submission Link: https://biomedres.us/submit-manuscript.php
4. Fedotov VG, Fedotova EY (2019) Conditions for air inflammation in the reactors of big volume. Contemp Chem 2(1): 1-3.

5. Fedotov VG, Fedotova EY (2018) The Negative Temperature Coefficient for the Nitrogen Oxidation Chain Reaction and its Effect on Super Luminescence Initiated by Electrical Discharge. J of Appl Phys \& Nanotechnol 11: 4

6. Fedotov VG, Fedotova EY (2015) The chain reaction of atmospheric nitrogen oxidation, initiated by electric discharge in air. J Phys Chem \& Biophys 5(6): 195.

7. Okabe H (1981) Photochemistry of small molecules.

8. Fedotov VG, Fedotova EY (2016) Chemical Kinetic Model of the chain reaction of atmospheric nitrogen oxidation initiated by electric discharge. Russian J Phys Chem B 10(5): 748-752.

$\begin{array}{ll}\text { BIOMEDICAL } & \text { Assets of Publishing with us } \\ \text { RESEARCHES } & \text { - Global archiving of articles } \\ & \text { - Immediate, unrestricted online access } \\ & \text { - Rigorous Peer Review Process } \\ \end{array}$

